\title{
Study of the Residual Strength of an RC Shear Wall with Fractal Crack Taking into Account Interlocking Interface Phenomena
}

\author{
O. Panagouli and K. Iordanidou \\ Laboratory of Structural Analysis and Design, Department of Civil Engineering, University of Thessaly, Pedion Areos, \\ 38334 Volos, Greece \\ Correspondence should be addressed to O. Panagouli; olpanag@uth.gr
}

Received 10 July 2013; Revised 25 September 2013; Accepted 2 October 2013

Academic Editor: Anaxagoras Elenas

Copyright (C) 2013 O. Panagouli and K. Iordanidou. This is an open access article distributed under the Creative Commons Attribution License, which permits unrestricted use, distribution, and reproduction in any medium, provided the original work is properly cited.

\begin{abstract}
In the present paper, the postcracking strength of an RC shear wall element which follows the construction practices applied in Greece during the 70s is examined by taking into account the complex geometry of the crack of the wall and the mixed frictionplastification mechanisms that develop in the vicinity of the crack. Due to the significance of the crack geometry, a multiresolution analysis based on fractal geometry is performed, taking into account the size of the aggregates of concrete. The materials (steel and concrete) are assumed to have elastic-plastic behaviour. For concrete, both cracking and crushing are taken into account in an accurate manner. On the interfaces of the crack, unilateral contact and friction conditions are assumed to hold. For every structure corresponding to each resolution of the interface, a classical Euclidean problem is solved. The obtained results lead to interesting conclusions concerning the influence of the simulation of the geometry of the fractal crack on the mechanical interlock between the two faces of the crack, a factor which seems to be very important to the postcracking strength of the lightly reinforced shear wall studied here.
\end{abstract}

\section{Introduction}

Many RC structures are facing a number of challenges, that is, earthquakes, hurricanes, and so forth, which may threaten their safety and serviceability. Therefore, modern structures built in seismic prone areas are designed to have significant bending and shear strength and ductility. However, existing structures designed according to earlier versions of the seismic codes and constructed using low strength materials usually have inadequate shear strength. For that, shear cracks appear in the shear wall elements of these structures reducing their overall capacity.

Generally, cracks are of large interest in RC structures since their properties reflect not only the condition of concrete as material but also the condition of the entire system at structural level. Crack width is commonly used as a convenient indicator of damage to RC elements, but it should be noted that the distribution and the geometry of the cracks are also important in measuring the extent of damage presented in the structure $[1,2]$ and in calculating the residual strength of it.

It is well known that the geometry of the interfaces of a crack is of fundamental importance to the study of friction, wear, and also strength evaluation. The recent research of fractured surfaces of various materials provides a deeper insight into the geometry of cracks. The corresponding research on metals [3] and on concrete and rocks [4-8] showed that the fractured surfaces hold fractal properties in a well-defined scale range. In the case of concrete the effects of aggregates sizes and the quality of concrete on the fractality of fractured surfaces were also investigated in [912], respectively. Therefore, an accurate description of the geometry of crack interfaces is of great importance for the simulation of contact. It is important to mention here that the actual contact between two real interfaces is realized only over a small fraction in a discrete number of areas. Consequently, the real contact area is only a fraction of the apparent area $[13,14]$, and the parameters of the actual 
contact regions are strongly influenced by the roughness of the contacting surfaces.

The multiscale nature of the surface roughness suggests the use of fractal geometry. The fractal approach adopted here for the simulation of the geometry of the cracks formed in a shear wall uses computer generated self-affine curves for the modelling of the interface roughness, which is strongly dependent on the values of the structural parameters of these curves. The computer generated fractal interfaces, which are based on a given discrete set of interface data, are characterized by a precise value of the resolution $\delta$ of the interface. This fact permits the study of the interface roughness on iteratively generated rough profiles, making this approach suitable for engineering problems, since it permits the satisfactory study of the whole problem with reliable numerical calculations.

The aim of this paper is to study how the resolution of a fractal crack $\mathscr{F}$ affects the strength of a reinforced concrete shear wall element. On the interface between the two cracked surfaces, unilateral contact and friction conditions are assumed to hold. The applied approach takes into account the nonlinear behaviour of the materials, including the limited strength of concrete under tension. The shear wall is submitted to shear loading. As a result of the applied approach, the contribution of the friction between the cracked surfaces is taken into account, as well as the additional strength coming from the mechanical interlock between the two faces of the crack. For every structure resulting for each resolution of the interface, a classical Euclidean problem is solved by using a variational formulation [15]. It must be mentioned here that the finest resolution of the interface is related to the size of the aggregates.

\section{Fractal Representation of Rough Surfaces}

The fractal nature of material damage has been a matter of a very intense research during the last three decades. The fractal nature of fractured surfaces in metals was shown more than 30 years ago by Mandelbrot et al. [3]. More specifically, it was shown that the fractured surfaces in metals develop a fractal structure over more than three orders of magnitude. In quasibrittle materials, observations have shown that fractured surfaces display self-affine scale properties in a certain range of scales which is in most cases very large and which greatly depends on the material microstructure. This is true for a large variety of quasibrittle materials such as rock, concrete, and ceramics [4-8, 16$18]$.

Fractal sets are characterized by noninteger dimensions [19]. The dimension of a fractal set in plane can vary from 0 to 2 . Accordingly, by increasing the resolution of a fractal set, its length tends to 0 if its dimension is smaller than 1 (totally disconnected set) or tends to infinity if it is larger than 1 . In these cases, the length is a nominal, useless quantity since it changes as the resolution increases. Conversely, the fractal dimension of a fractal set is a parameter of great importance because of its scale-independent character.

Many methods which are based on experimental or numerical calculations, such as the Richardson method [19], have been developed for the estimation of the fractal dimension of a curve. According to this method, dividers, which are set to a prescribed opening $\delta$, are used. Moving with these dividers along the curve so that each new step starts where the previous step leaves off, one obtains the number of steps $N(\delta)$. The curve is said to be of fractal nature if, by repeating this procedure for different values of $\delta$, the relation

$$
N(\delta) \sim \delta^{-D}
$$

is obtained in some interval $\delta^{*}<\delta<\Delta^{*}$. The power $D$ denotes the fractal dimension of the profile, which is in the range $1<D<2$. The relation between the fractal dimension $D$ of this profile and the dimension of the corresponding surface is $D_{s}=D+1[16]$.

In relation (1) there is an upper and a lower bound in the scaling range and, consequently, a transition from the fractal regime at the microscopic level to the Euclidean regime at largest scales. The upper bound is represented by the macroscopic size of the set, while the lower one is related to the size of the smallest measurable particles, that is, the aggregates in the case of concrete. Mandelbrot [20] first pointed out the transition from a fractal regime characterized by noninteger dimensions to the homogeneous one characterized by classical topological dimensions, a fact which points out the main difference between mathematical and physical fractals.

The idea of self-affinity is very popular in studying surface roughness because experimental studies have shown that, under repeated magnifications, the profiles of real surfaces are usually statistically self-affine to themselves $[3,21]$. The self-affine fractals were used in a number of papers as a tool for the description of rough surfaces [22-28]. Typically, such a profile can be measured by taking height data $y_{i}$ with respect to an arbitrary datum at $N$ equidistant discrete points $x_{i}$. In the sequence, fractal interpolation functions $\mathscr{F}\left(x_{i}\right)=y_{i}, i=0,1, \ldots, N$ are used for the passage from this discrete set of data $\left\{\left(x_{i}, y_{i}\right), i=0,1,2, \ldots, N\right\}$ to a continuous model. According to the theory of Barnsley [29], the sequence of functions $\mathscr{F}_{n+1}(x)=\left(T \mathscr{F}_{n}\right)(x)=c_{i} l_{i}^{-1}(x)+$ $d_{i} \mathscr{F}_{n}\left(l_{i}^{-1}(x)\right)+g_{i}$ converges to a fractal curve $\mathscr{F}$ as $n \rightarrow \infty$. The transformation $l_{i}$ transforms $\left[x_{0}, x_{N}\right]$ to $\left[x_{i-1}, x_{i}\right]$, and it is defined by the relation $l_{i}(x)=a_{i} x+b_{i}$. The calculation of the parameters $a_{i}, b_{i}, c_{i}$, and $g_{i}$ is based on the given set of data and the free parameters $d_{i}$.

Fractal interpolation functions give profiles which look quite attractive from the viewpoint of a graphic roughness simulation. In higher approximations, these profiles appear rougher as it is shown in the next section where the first to fifth approximations of a fractal interpolation function are presented. Moreover, the roughness of the profile is strongly affected by the free parameters $d_{i}$ of the interpolation functions. As these parameters take larger values, the resulting profiles appear rougher with sharper peaks. 


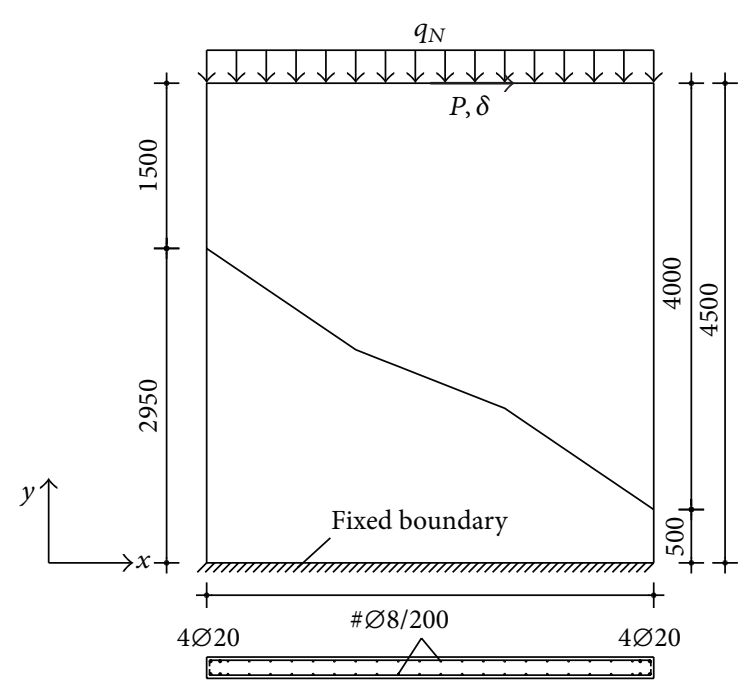

Figure 1: The considered shear wall.

Another model of self-affine profiles, which can be used for roughness description, is the multilevel hierarchical profile. This profile has a hierarchical structure and is constructed by using a certain iterative scheme presented in [24]. As in the case of the fractal interpolation functions, the surfaces produced by this scheme are characterized by a precise value of the resolution $\delta$ of the fractal curve. More specifically, in both cases, the iterative construction of the profiles permits us to analyse "prefractals" of arbitrary generation and, therefore, of arbitrary resolution $\delta_{n}$.

It must be mentioned here that an important advantage of the fractal interpolation functions presented in [29] and of the multilevel hierarchical approach presented in [24] is that their fractal dimension can be obtained analytically and it depends strongly on their construction parameters. Thus, in the case of fractal interpolation functions which are used in this paper for the simulation of the geometry of the crack, the fractal dimension $D$ is given by the relation

$$
\sum_{i=1}^{N}\left|d_{i}\right| a_{i}^{D-1}=1
$$

\section{Description of the Considered Problem}

In Figure 1, an RC shear wall element which follows the construction practices applied in Greece during the 70s is presented. More specifically, the wall is reinforced by a double steel mesh consisting of horizontal and vertical rebars having a diameter of $8 \mathrm{~mm}$ and a spacing of $200 \mathrm{~mm}$. The quality of the steel mesh is assumed to be S220 (typical for buildings of that age). At the two ends of the wall, the amount of reinforcement is higher. Four $20 \mathrm{~mm}$ rebars of higher quality (S400) are used without specific provisions to increase the confinement. The thickness of the wall is $200 \mathrm{~mm}$ and the quality of concrete is assumed to be C16, typical for this kind of constructions. The wall is fixed on the lower horizontal boundary.
TABLE 1: Characteristics of the considered structures.

\begin{tabular}{lcc}
\hline Iteration $(n)$ & Resolution $\delta_{n}(\mathrm{~m})$ & Interface length $L_{n}(\mathrm{~m})$ \\
\hline 1st & 1.404 & 4.888 \\
2nd & 0.468 & 4.946 \\
3rd & 0.156 & 5.080 \\
4th & 0.052 & 5.373 \\
5th & 0.017 & 5.935 \\
\hline
\end{tabular}

The considered shear wall is divided into two parts by a crack which has been formed due to shear failure of concrete. It is important to be mentioned here that, in low strength concretes, as in the case examined here, the fractured surfaces are rougher compared to the fractured surfaces developed in high strength concretes [12] because in the first case the cracks are developed in the contact zone between the aggregates and the cement paste, whereas in the second case the failure of the aggregates ensures a less rough interface. For the description of the roughness of the crack, the notion of fractals is used. More specifically, the crack is described by a fractal interpolation function which interpolates the set of data $\{(-1.0,2.95),(0.4,2.0),(1.8,1.0),(3.2,0.5)\}$. The free parameters of the function are taken to have the values $d_{1}=$ $d_{2}=d_{3}=0.50$ in order for the interface to be rough (the fractal dimension of the interface results to be equal to 1.369).

The computer generated interfaces $\mathscr{F}_{n}, n=1,2, \ldots$ are "prefractals" images of the fractal set characterized by a precise value of the resolution $\delta_{n}$, which is related to the $n$th iteration of the fractal interpolation function and represents the characteristic linear size of the interface. As it is shown in Figure 2 where five iterations of a fractal interface are given, the linear size of the interface changes rapidly when higher iterations are taken into account. In Table 1, the characteristics of each resolution are presented. More specifically, in the second column, the resolution of the interface $\delta_{n}$ is given, whereas in the third column the total crack length $L_{n}$ is presented.

The objective here is to estimate the capacity of the shear wall under an action similar to the one that has created the crack. For this reason, a horizontal displacement of $20 \mathrm{~mm}$ is applied on the upper side of the wall (see Figure 1). Moreover, a vertical distributed loading $q_{N}$ is applied on the upper horizontal boundary, creating a compressive axial loading. The resultant of this loading is denoted by $N$. For $N$, six different values will be considered from 0 to $2.500 \mathrm{kN}$ with a step of $500 \mathrm{kN}$.

For the modelling of the above problem it is assumed that the opposite sides of the fracture are perfectly matching surfaces in a distance of $0.1 \mathrm{~mm}$ and the finite element method is used. In order to avoid a much more complicated three-dimensional analysis, two-dimensional finite elements were employed; however, special consideration was given to the incorporation of the nonlinearities that govern the response of the wall. More specifically, the mass of concrete was modelled through quadrilateral and triangular plain stress elements. The finite element discretization density is similar for all the considered problems [30] in order for the discretization density not to affect the comparison between 


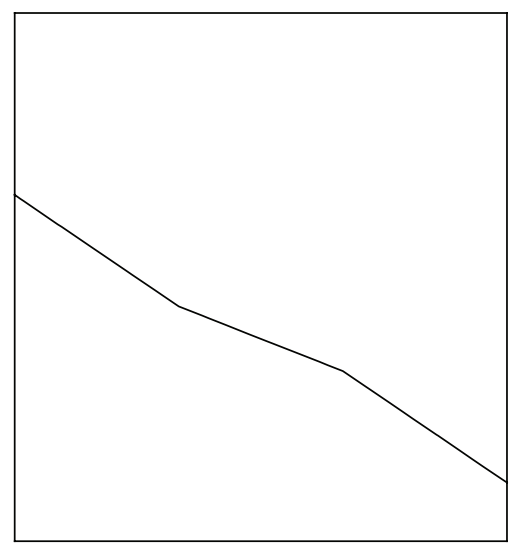

1st resolution

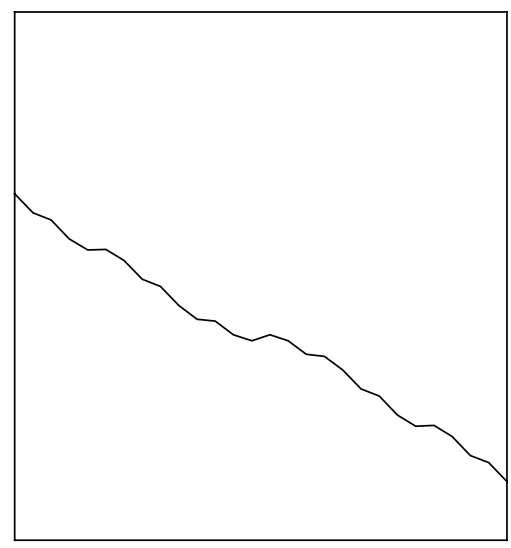

3rd resolution

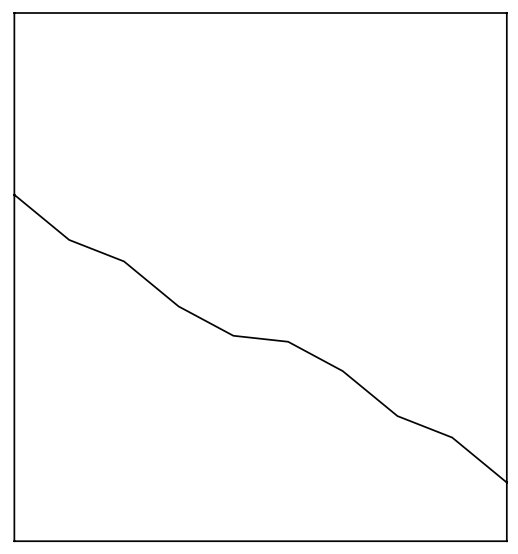

2nd resolution

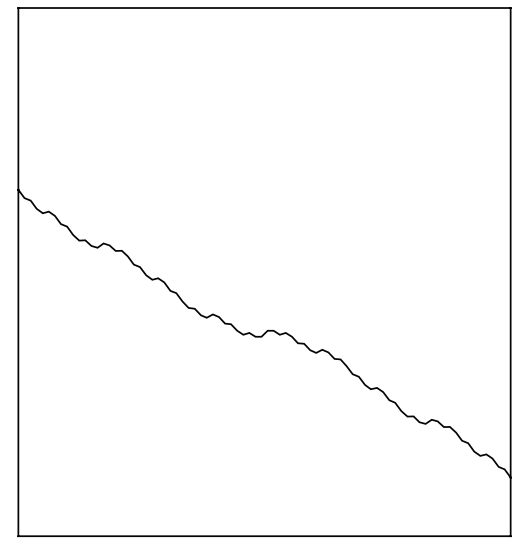

4th resolution

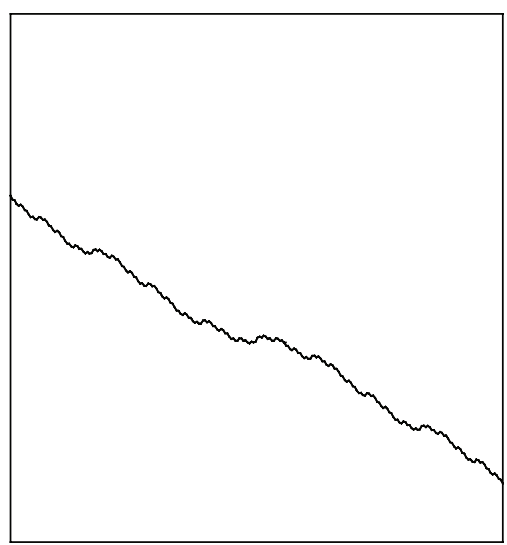

5th resolution

FIgURE 2: The first five resolutions of the fractal crack.

the results of the various analyses that were performed. The modulus of elasticity for the elements representing the mass of concrete was taken to be equal to $E=21 \mathrm{GPa}$ and the Poisson's coefficient to be equal to $v=0.16$. The material was assumed to follow the nonlinear law depicted in Figure 3(a). Under compression, the material behaves elastoplastically, until a total strain of 0.004 . After this strain value crushing develops in concrete, leading its strength to zero. A more complicated behaviour is considered under tension. More specifically, after the exhaustion of the tension strength of concrete, a softening branch follows, having a slope $k_{s}=$ $10 \mathrm{GPa}$. Progressively the tension strength of concrete is also zeroed. The above unidirectional nonlinear law is complemented by an appropriate yield criterion (Tresca) which takes into account the two-dimensional stress fields that develop in the considered problem. For the simulation of cracking, a smeared crack algorithm is used, in which the cracks are evenly distributed over the area of each finite element [31].

The steel rebars were modelled through two-dimensional beam elements, which were connected to the same grid of 


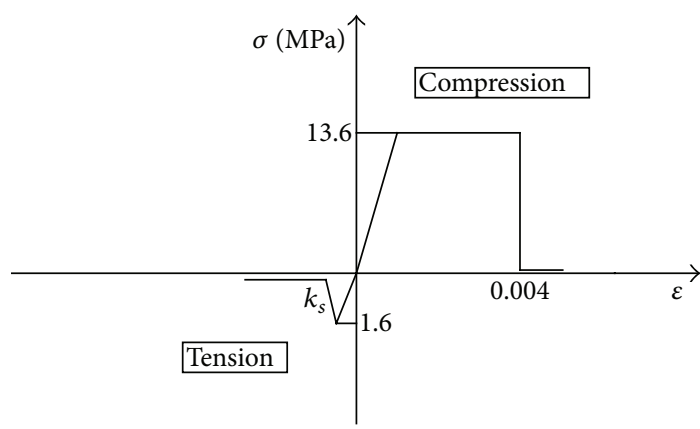

(a)

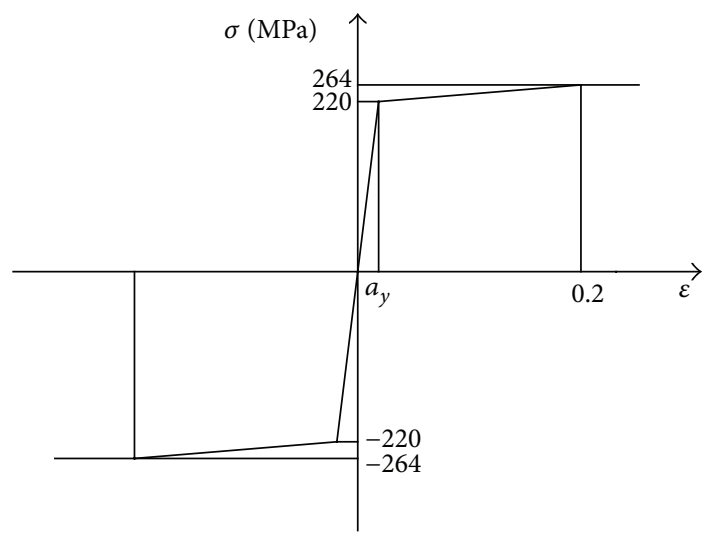

(b)

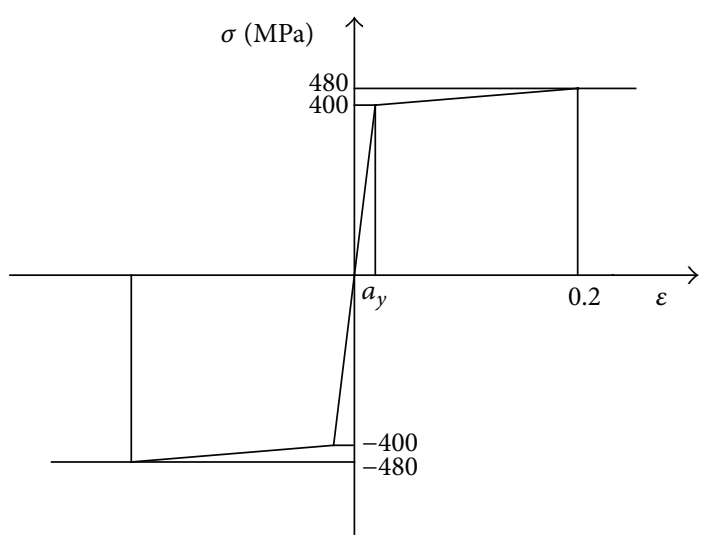

(c)

FIgURE 3: The adopted materials laws: (a) C16 concrete, (b) S220 steel, and (c) S400 steel.

nodes as the plain stress elements simulating the concrete. At each position, the properties that were given to the steel rebars take into account the reinforcement that exists in the whole depth of the wall. For example, the horizontal and vertical elements that simulate the steel mesh are assigned an area of $100.48 \mathrm{~mm}^{2}$ that corresponds to the cross-sectional area of two $8 \mathrm{~mm}$ steel rebars. For simplicity, the edge reinforcements $(4 \phi 20)$ were simulated by a single row of beam elements that have an area of $1256 \mathrm{~mm}^{2}$ (i.e., $4 \times 314 \mathrm{~mm}^{2}$ ). For the steel rebars, a modulus of elasticity $E=210 \mathrm{GPa}$ was assumed. Moreover, the nonlinear laws of Figures 3(b) and 3(c) which exhibit a hardening branch, after the yield stress of the material is attained, were considered for S220 and S400 steel qualities, respectively.

Figure 4 depicts the finite element discretizations for the structures that correspond to the third, fourth, and fifth iterations of the fractal crack. The grey lines in the finite element meshes correspond to the positions; of the steel rebars. Special attention was given in the modelling so that the steel rebars retain their initial horizontal and vertical positions, that is, no eccentricity exists between the corresponding rows of beam finite elements due to the formation of the crack.

In this paper, only the finite element models corresponding to the $3 \mathrm{rd}, 4 \mathrm{th}$, and 5 th resolutions of the fractal crack were considered, because 1st and 2nd resolutions do not have a meaning from the engineering point of view. On the other hand, the 5 th resolution gives a good lower bound of $\delta$ because $\delta_{5}$ is related to the size of the aggregates of concrete.

At the interfaces, unilateral contact and friction conditions were assumed to hold. The Coulomb's friction model was followed with a coefficient equal to 0.6. At each scale, a classical Euclidean problem is solved by using a variational formulation [15].

For every value of the vertical loading $N$, a solution is taken in terms of shear forces and horizontal displacements at the interface, for different values of the resolution of the cracked wall and for the case of the uncracked wall. The aim of this work is to study the behaviour of the shear wall, that is, the behaviour of concrete and the forces in the rods, as the vertical loading and the resolution of the interface change.

Two cases are considered:

(i) In the first case, the wall is uncracked;

(ii) In the second case, where a fractal crack $\mathscr{F}$ has been developed in the wall, different resolutions are taken into account in order to examine how the resolution of a fractal interface $\mathscr{F}$ affects the strength of the RC shear wall element. 

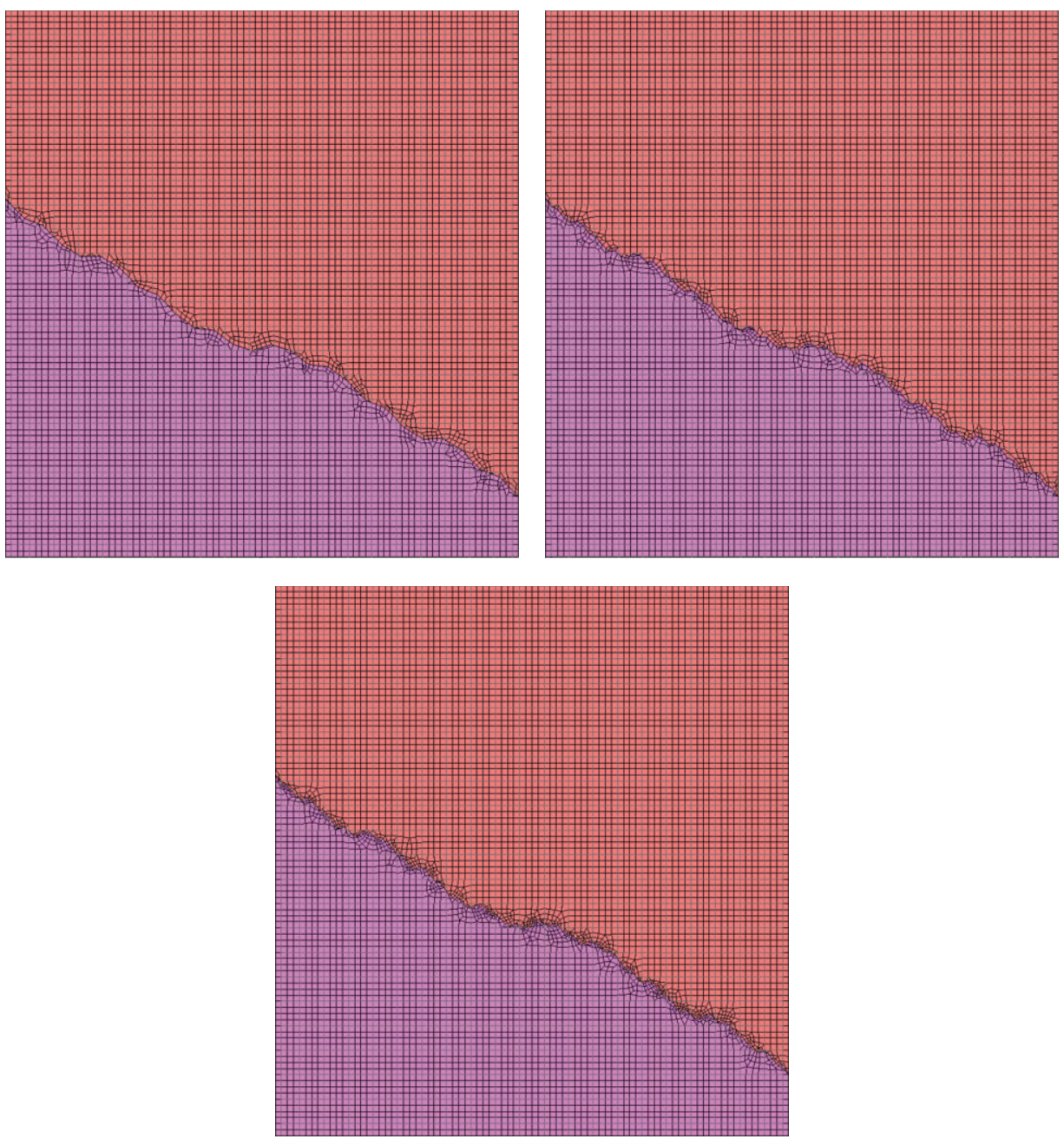

FIGURE 4: FE discretizations for third, fourt, and fifth resolutions of the fractal interface.

The solution of the above problems is obtained through the application of the Newton-Raphson iterative method. Due to the highly nonlinear nature of the problem, a very fine load incrementation was used. The maximum value of the horizontal displacement $(20 \mathrm{~mm})$ was applied in 2000 loading steps, while the total vertical loading was applied in the 1st load step and was assumed as being constant in the subsequent steps.

\section{Numerical Results}

Figure 5 presents the applied horizontal load versus the corresponding displacement ( $P-\delta$ curves) for the different values of vertical loading $N$. Starting from the case of the uncracked wall, it must be mentioned that the value of the vertical loading plays a significant role. As the value of the vertical loading increases, the capacity of the wall to undertake horizontal loading increases as well. However, for higher load values (for $N=2.000$ and $2.500 \mathrm{kN}$ ), strength degradations due to the exhaustion of the shear strength of concrete are noticed. In the sequel, the resistance of the wall increases again as a result of the transfer of the loading from concrete to the horizontal steel rebars.

In cases of the cracked walls, the beneficial effect of the normal compressive loading is once more verified. This result holds for the 3rd, the 4th, and the 5th resolutions of the fractal crack but for small displacement values only. For larger displacement values, the three variants of the cracked wall behave differently. The 4th and the 5th resolutions appear to have a stable behaviour without strength degradations. However, it is noticed that, in the case of the 3rd resolution and for heavy axial loading, significant strength degradation takes place.

The above results can be more easily understood if we compare in the same diagram the curves obtained for the four different structures studied here (uncracked, 3rd resolution, 4th resolution, and 5th resolution) for specific load levels. In Figure 6, the $P-\delta$ curves for three cases of axial loading $(N=0, N=1500 \mathrm{kN}$, and $N=2.500 \mathrm{kN})$ are presented. We observe that, for low values of the compressive axial loading, there is actually no difference between the uncracked and the cracked walls. In all cases, the horizontal loading is easily transferred and no signs of strength degradation are noticed 

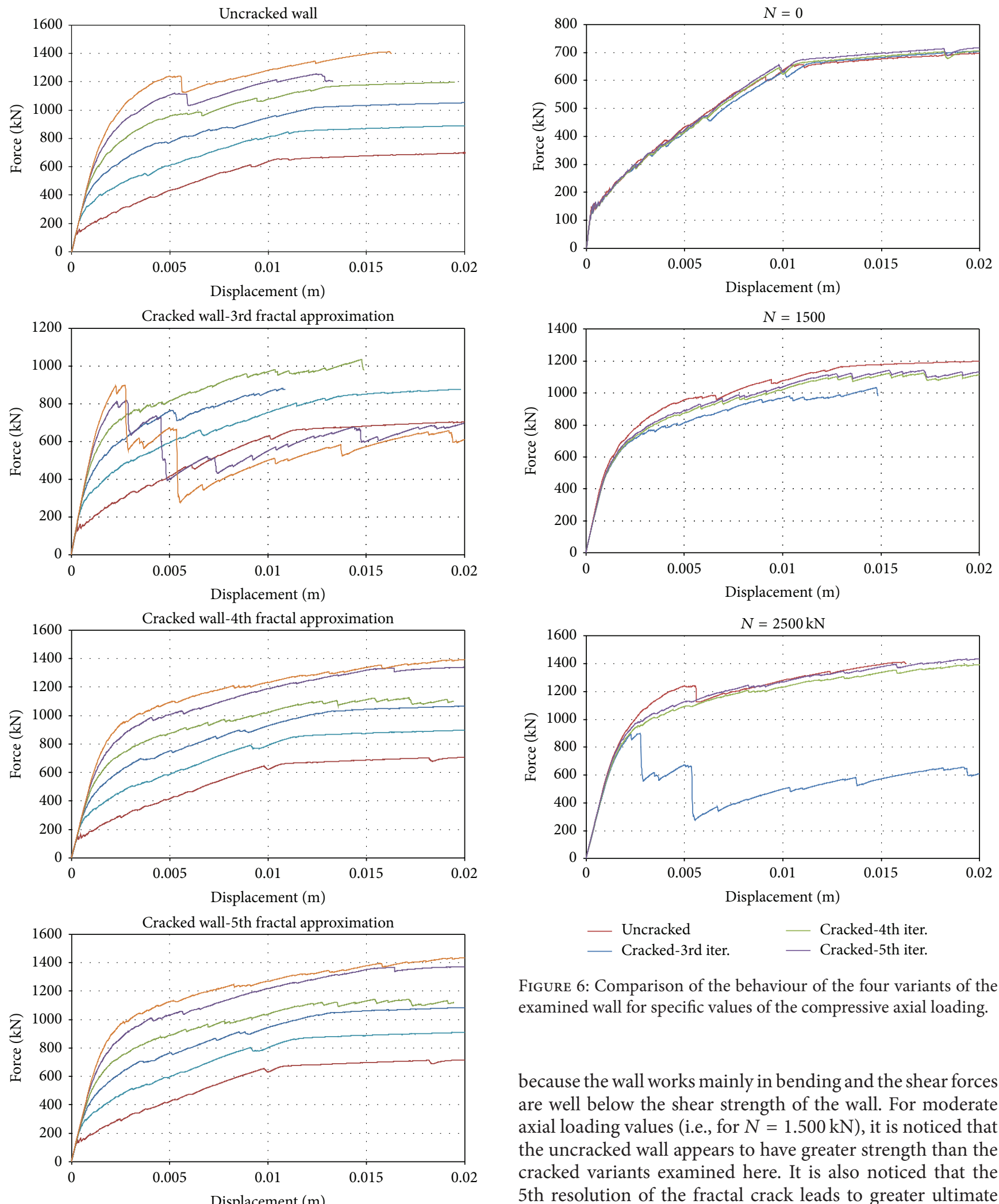

Uncracked
Cracked-3rd iter Cracked-4th iter.

Figure 6: Comparison of the behaviour of the four variants of the examined wall for specific values of the compressive axial loading.

because the wall works mainly in bending and the shear forces are well below the shear strength of the wall. For moderate axial loading values (i.e., for $N=1.500 \mathrm{kN}$ ), it is noticed that the uncracked wall appears to have greater strength than the cracked variants examined here. It is also noticed that the 5 th resolution of the fractal crack leads to greater ultimate strength, a result which can be attributed to the fact that the 5 th resolution seems to lead to a greater degree of interlocking between the two interfaces of the crack.

However, the most interesting case is the case where FIgURE 5: Load-displacement $(P-\delta)$ curves for the cases of the uncracked and cracked walls. First, it can be noticed that the behaviour of the 4 th and 

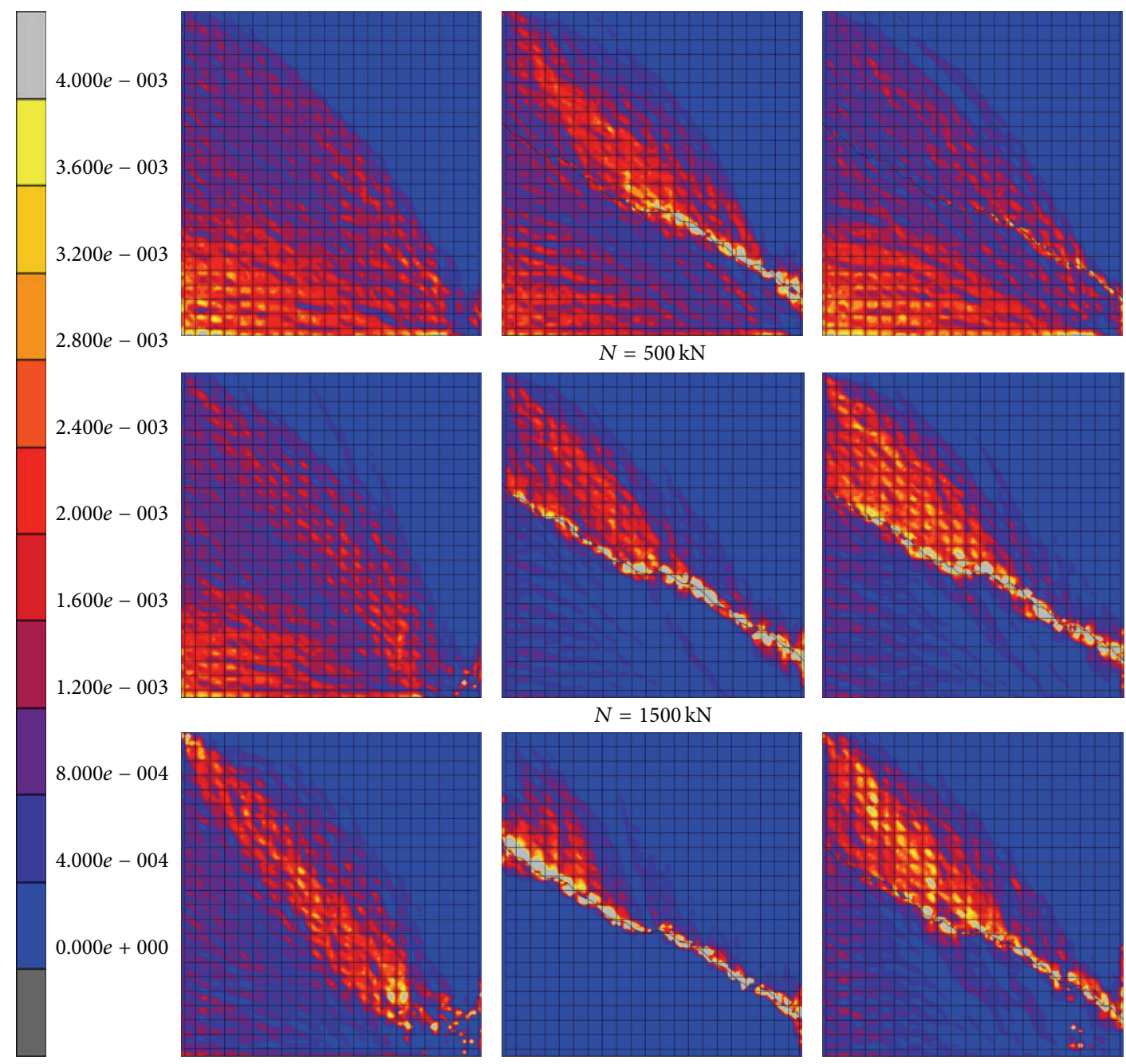

$N=2500 \mathrm{kN}$

FIGURE 7: Cracking strains for various values of the vertical loading, for the cases of the uncracked wall (left column) and the cracked walls (3rd resolution: middle column and 4 th resolution: right column).

the 5th resolutions of the crack leads to results that are close enough to those of the uncracked wall. There exist some differences between the uncracked and the cracked walls for horizontal displacements in the range of $2 \mathrm{~mm}-6 \mathrm{~mm}$, where the uncracked wall exhibits greater resistance. However, when the horizontal displacement reaches the value of $6 \mathrm{~mm}$, the uncracked wall appears to have strength degradation, and after this displacement value the results of the 4 th and the 5 th resolutions of the fractal crack are again very close to those of the initially uncracked wall.

Significantly different is the behaviour of the 3rd resolution of the fractal crack. Although in the first loading steps the results are close to those of the 4 th and 5 th resolutions, after a displacement value of $2.5 \mathrm{~mm}$, significant strength degradation appears, having the form of successive vertical branches. Moreover, the ultimate strength of this wall is significantly lower than the other variants.
It is interesting to try to explain this significantly different behaviour that appears between the walls corresponding to the 3rd and the higher resolutions of the fractal crack. For this reason, all the parameters affecting the behaviour of the wall will be comparatively studied in the sequel.

Figure 7 depicts the cracking strains of concrete for specific values of the axial loading. All the depicted results correspond to the end of the analysis; that is, they have been obtained for an applied horizontal displacement of $20 \mathrm{~mm}$. First of all, it can be noticed that, for low values of axial loading, the cracking patterns that have been developed in all the studied walls are rather similar. The larger cracking strain values (yellow and grey colours) have their nature in the bending deformation of the wall. For moderate axial loading, the cracking patterns are quite different. The uncracked wall presents a bending type cracking pattern. The cracked walls (3rd and 4 th resolutions) seem to behave differently. Both of them exhibit significant cracking in the vicinity of the crack 

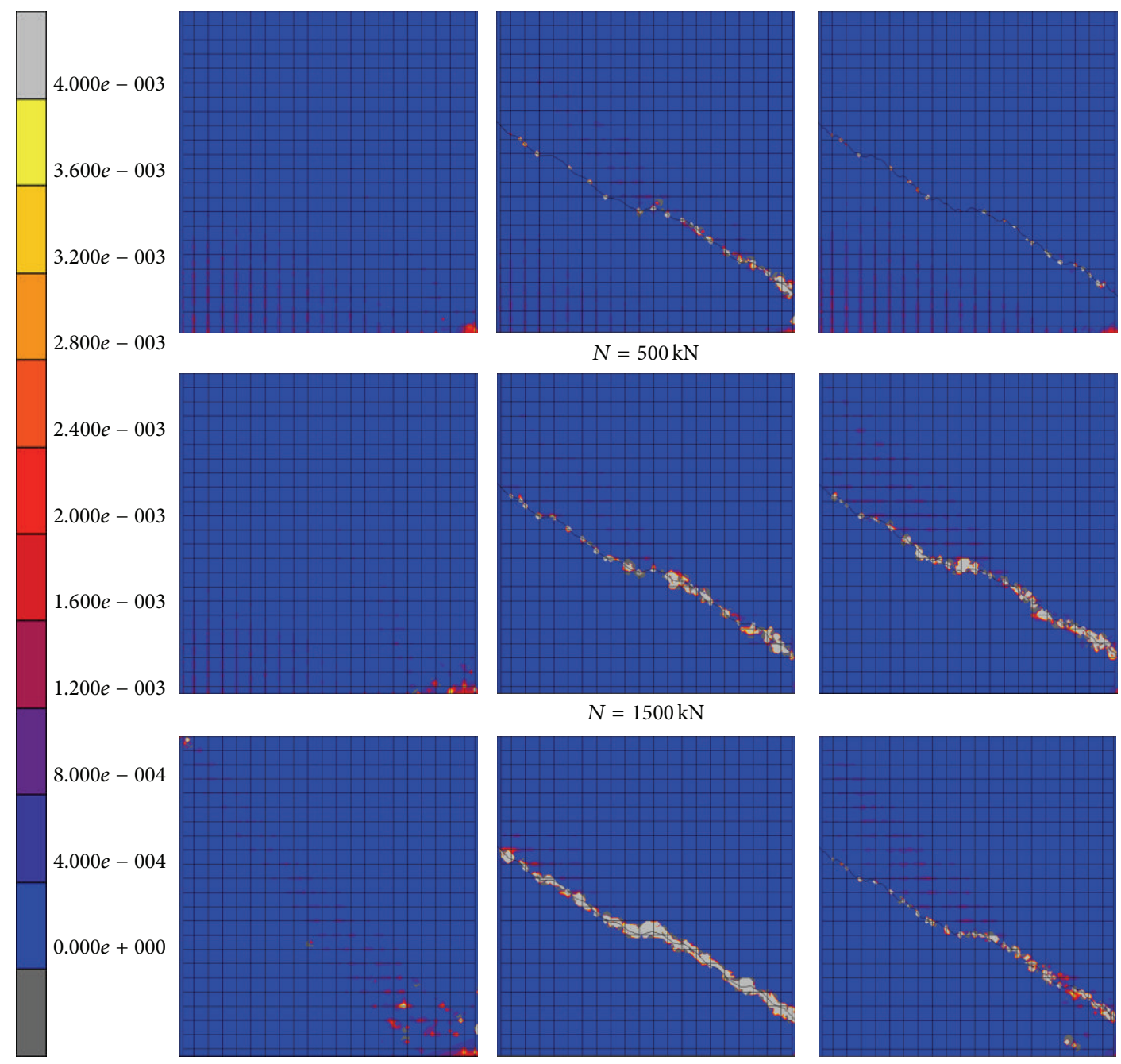

$N=1500 \mathrm{kN}$
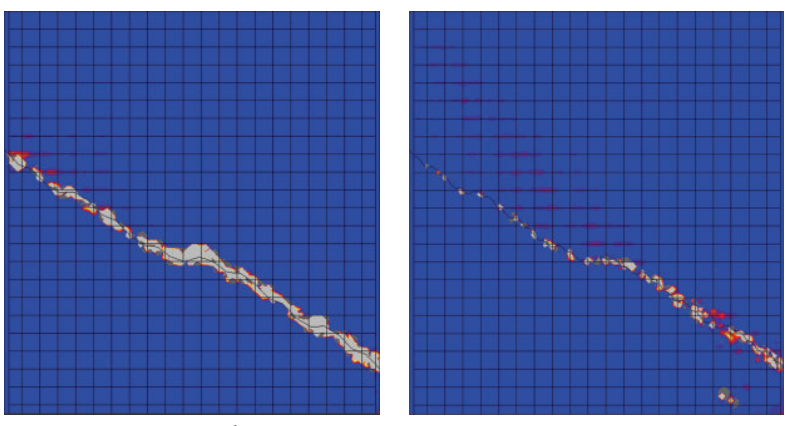

$N=2500 \mathrm{kN}$

FIGURE 8: Plastic strains for various values of the vertical loading, for the cases of the uncracked wall (left column) and the cracked walls (3rd resolution: middle column and 4th resolution: right column).

(grey colours). Moreover, shear type cracking patterns are developed at the upper parts of the walls.

The above results alone cannot explain the significantly different responses that the two cracked variants of the wall exhibit. For this reason, the plastic strains of concrete obtained for the same applied horizontal displacement are examined. Figure 8 depicts the plastic concrete strains for the three different variants of the wall and for specific values of axial loading. The upper value of the presented scale corresponds actually to the crushing limit (grey values). Therefore, it can be considered that concrete stresses in these areas are actually zero. For the uncracked wall (left column of Figure 8) it can be noticed that the more heavily deformed region is the lower right corner. It is clear that in this case the wall exhibits a typical bending type deformation behaviour (cracking at the lower left region, crushing at the lower right corner).

On the other hand, the cracked walls seem to deform significantly in the vicinity of the crack. This phenomenon is more pronounced in the case of the 3rd resolution of the fractal wall and especially in the case of heavy axial loading, where it can be noticed that the vicinity of the crack is in the crushed state; that is, the forces are transmitted solely by the steel mesh in this region. For the case of the 4 th resolution, this phenomenon is rather limited; that is, it can be concluded that in this case the crack retains partially its ability to transfer shear and compressive forces through the contact and friction phenomena developed in the interface and through the mechanical interlocking that occurs between the two interface parts.

In the sequel, it is interesting to examine the deformations that have occurred at the steel mesh. Figure 9 displays the steel mesh for the cases studied above. The presented deformations which correspond to the last load step have been magnified by a factor of 10 so that the differences between the examined cases are visible. It is obvious that, for low vertical loading values, the deformations of the steel meshes are actually very similar. However, for moderate 

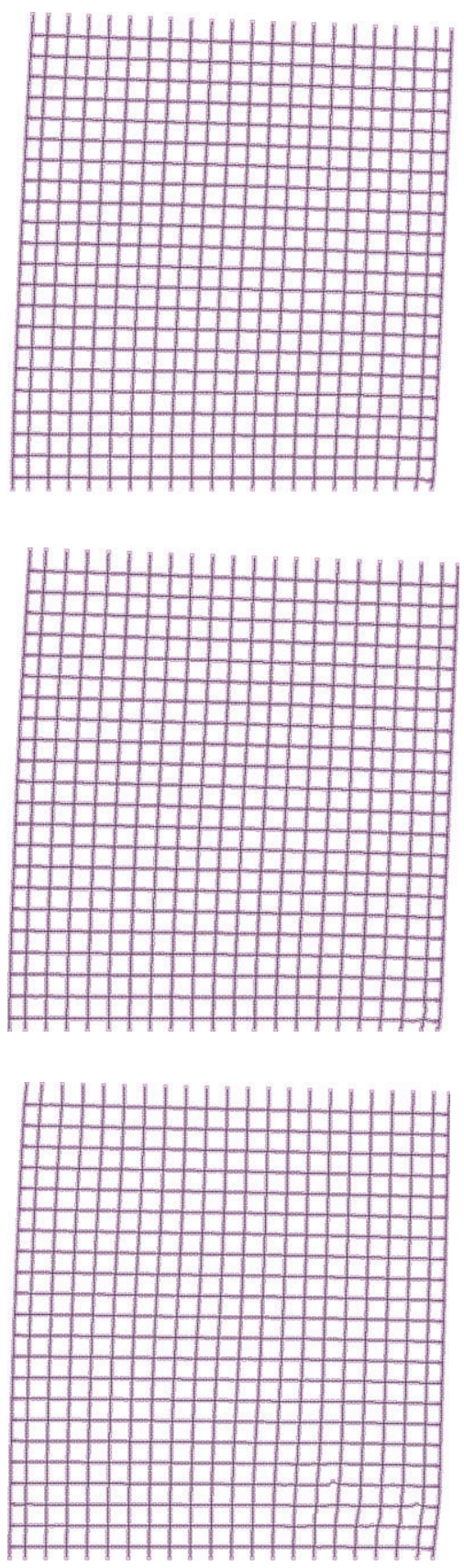

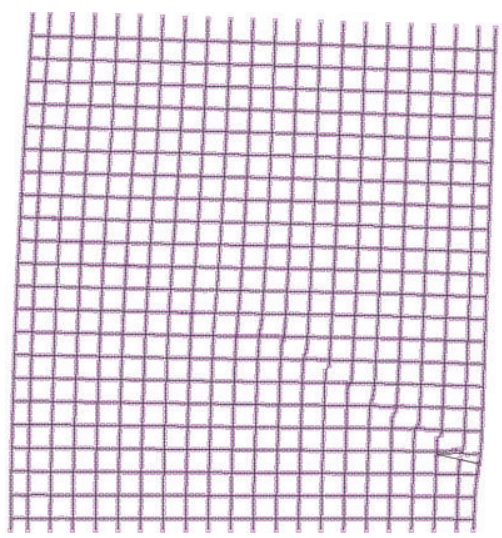

$N=500 \mathrm{kN}$

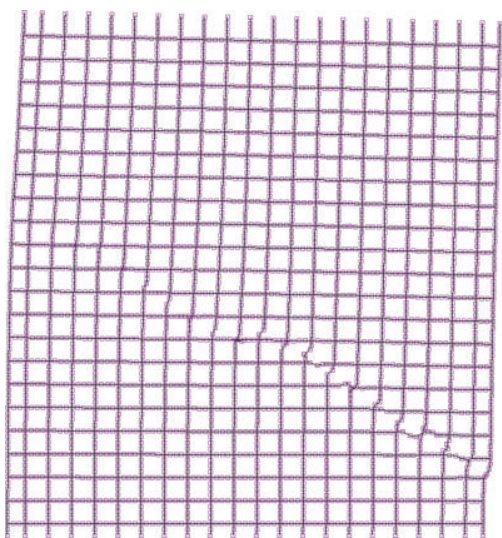

$N=1500 \mathrm{kN}$

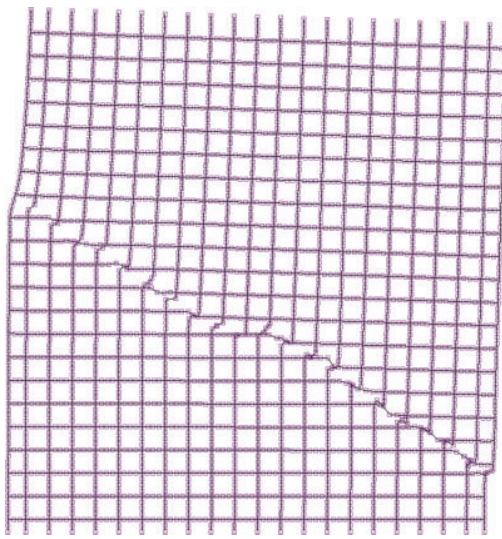

$N=2500 \mathrm{kN}$
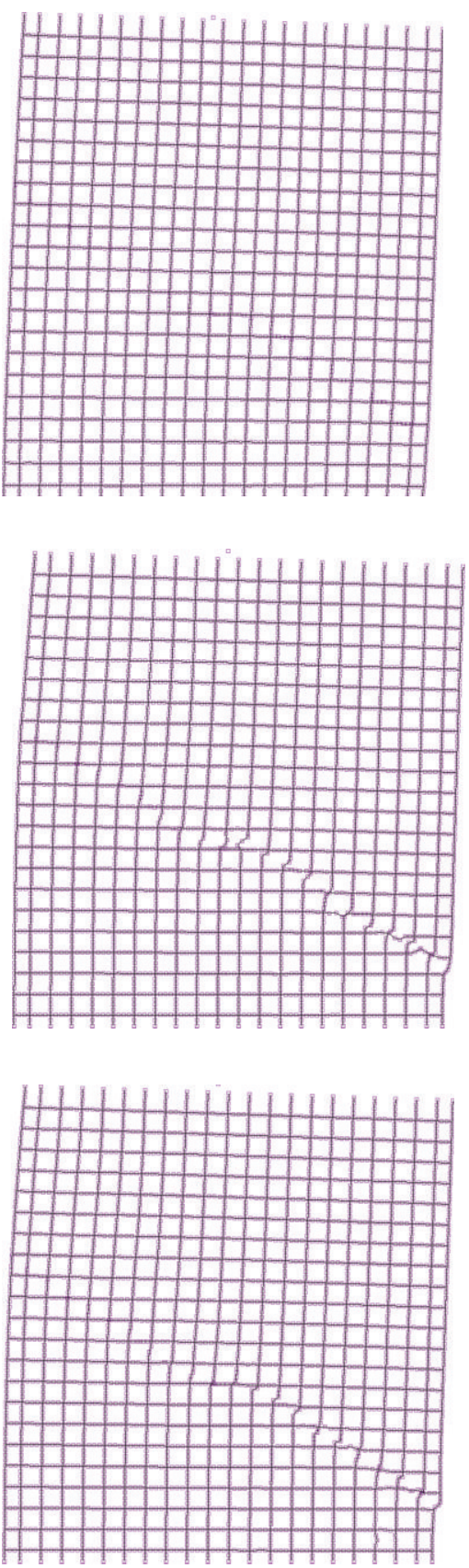

FIGURE 9: Deformation of the steel mesh for various values of the vertical loading, for the cases of the uncracked wall (left column) and the cracked walls (3rd resolution: middle column and 4th resolution: right column).

values of the vertical loading $(N=1.500 \mathrm{kN})$, there exist some differences. The steel meshes of the cracked walls seem to be distorted in the vicinity of the right part of the formed crack. In this region, the vertical rebars above and below the crack present an offset which can be attributed to the inability of the interface to transfer shear forces. For the case of heavy vertical loading, the situation is much different. The wall corresponding to the 4 th resolution of the fractal crack has a deformation similar to that of the case of moderate loading. However, the steel mesh of the wall corresponding to the 3rd resolution of the fractal crack exhibits significant deformations along the crack. More specifically, the upper vertical rebars present a significant horizontal offset with respect to the lower ones. This horizontal offset is obvious even in the leftmost part of the wall. Moreover, the horizontal rebars of the upper part present a vertical offset with respect to the ones of the lower part. This deformation pattern of the steel mesh verifies the findings that were noticed in 

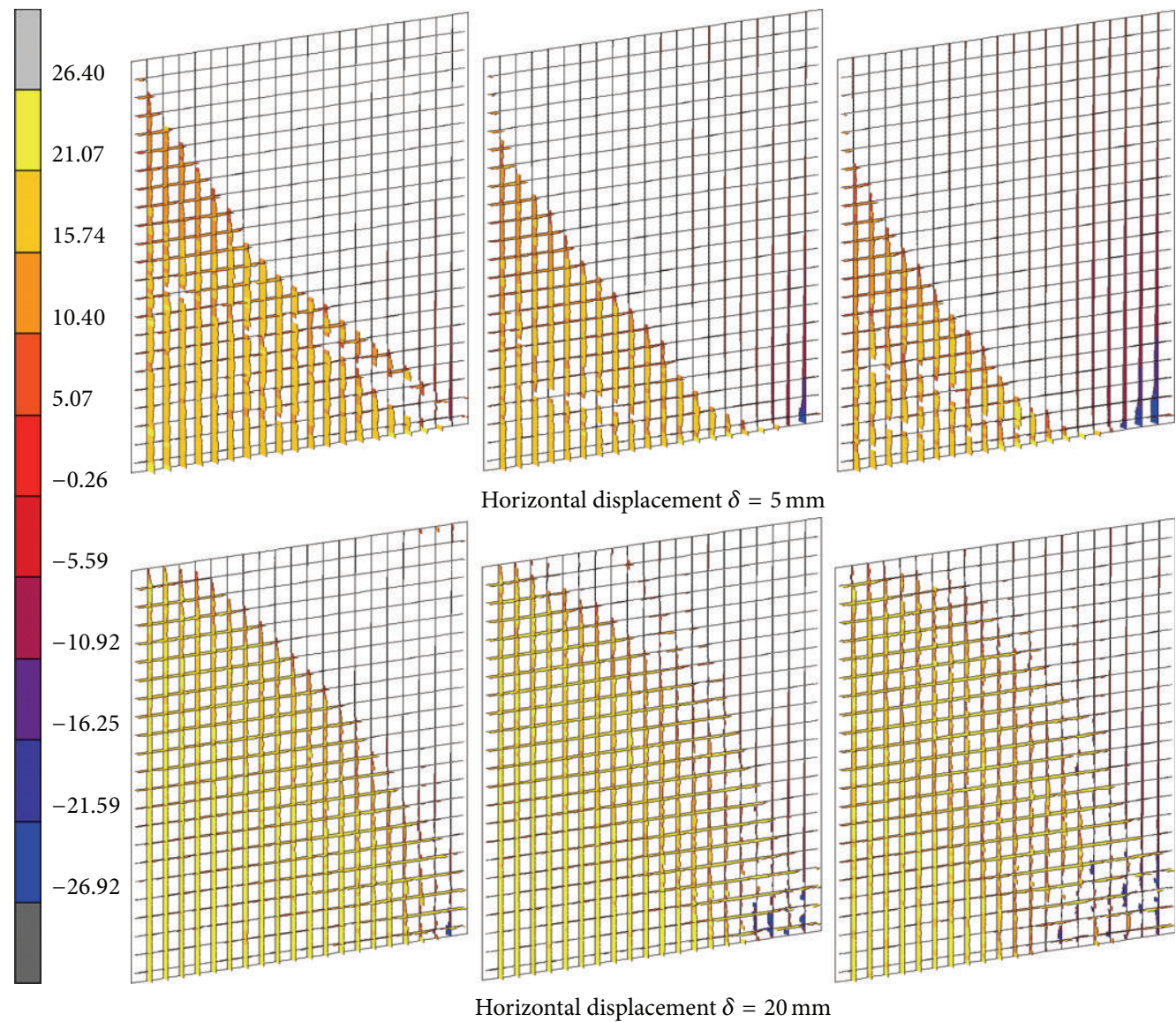

Horizontal displacement $\delta=20 \mathrm{~mm}$

FIGURE 10: Forces developed in the steel mesh for various values of the vertical loading for the uncracked wall (left column: $N=500 \mathrm{kN}$, middle column: $N=1500 \mathrm{kN}$, and right column: $N=2500 \mathrm{kN}$ ).

Figure 8 concerning the excessive strains in the vicinity of the crack (which had values well above the crushing strain limit) resulting from the inability of concrete to transfer any loading in this case.

Now, the difference in the response between the 3rd and the 4th resolutions of the fractal crack for the case of heavy vertical loading will be explained. As it has already been noticed, higher vertical loading leads to higher values of the horizontal loading. The increased horizontal forces have to be transferred from the upper part of the cracked wall to its lower part. In this respect, three mechanisms are developed in order to facilitate the horizontal load transfer:

(i) exploitation of the tensile strength of the horizontal rebars;

(ii) development of friction on the part of the crack where contact forces occur;

(iii) mechanical interlock between the two interfaces of the crack.

The first two mechanisms are almost similar in both cracked walls. However, it is obvious from Figure 6 that in higher resolutions fractal crack improves its capacity to transfer forces through the mechanical interlock mechanism.
According to the authors' opinion, this fact is the main reason for the difference in the response between the walls corresponding to the 3rd and the 4th resolutions of the fractal crack. For lower vertical load values the differences are rather limited; however, as the vertical loading increases, the response is completely different because the increased vertical forces are combined with the increased horizontal forces and "destroy" completely the vicinity of the interface.

Figures 10, 11, and 12 display the forces developed at the horizontal and vertical rebars of the steel mesh for the three variants of the wall examined here for displacements of $5 \mathrm{~mm}$ and $20 \mathrm{~mm}$. The left column of each figure corresponds to lower values of the axial loading $(N=500 \mathrm{kN})$, the middle column to moderate loading values $(N=1500 \mathrm{kN})$, and the right column to heavy axial loading $(N=2.500 \mathrm{kN})$.

For the case of the uncracked wall (Figure 10), it is noticed that, in the early horizontal loading steps $(\delta=5 \mathrm{~mm})$, only the vertical rebars are significantly loaded. The rebars in the left side of the wall have tensile forces while the rebars in the right side develop compressive forces, as a result of the bending of the wall. For $\delta=20 \mathrm{~mm}$, after the development of cracking in various parts of the initially uncracked wall, the horizontal rebars are also stressed, mainly in the areas where the corresponding cracks have 

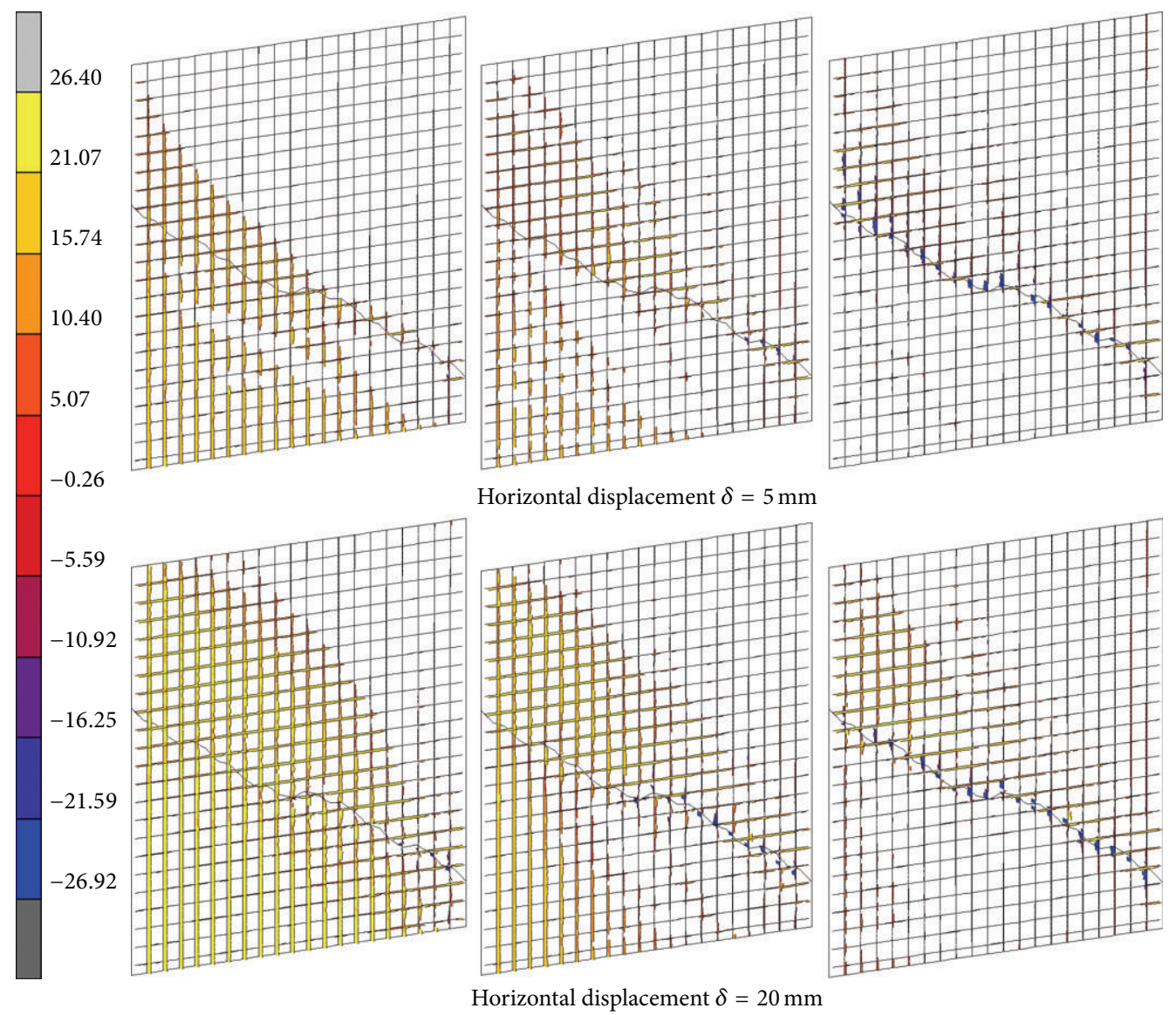

FIGURE 11: Forces developed in the steel mesh for various values of the vertical loading for the 3rd resolution of the crack (left column: $N=500 \mathrm{kN}$, middle column: $N=1500 \mathrm{kN}$, and right column: $N=2500 \mathrm{kN}$ ).

reduced or zeroed the ability of concrete to transfer shear forces.

For the case of the 3rd resolution of the crack (Figure 11), it is noticed that the vertical rebars are stressed only for small axial loading values. For moderate and heavy axial loading, the vertical rebars are partially only stressed. It deserves to be noticed that the rebar stresses are negative in the vicinity of the crack, a fact which verifies that the concrete is unable to transfer even compressive loading. Moreover, it is noticed that the rebars of the right side of the wall do not develop compressive stresses any more, due to the fact that the magnitude of bending that develops in this case is significantly smaller than that in the case of the uncracked wall. The horizontal rebars are stressed only in specific areas, near the crack and in the regions where cracking strains have been developed. In any case, a closer look in the forces that have been developed in the rebars verifies the significantly decreased bending capacity of the specific wall.

The situation is rather different in the case of the 4 th resolution of the fractal crack (Figure 12). It can easily be verified that, for small values of the axial loading, the picture of the forces of the vertical rebars is quite similar to that of the uncracked wall. The same holds also for the forces of the horizontal rebars. For moderate axial load values, the forces of the vertical rebars appear to be discontinuities. At the right part of the crack, it can be noticed that in some rebars the forces are compressive, indicating once again the partial inability of concrete in this region to transfer compressive loading. The horizontal rebars are mainly stressed in the upper part of the cracked wall and in the vicinity of the crack. This result is absolutely compatible with the remarks given for the cracked areas in Figure 7.

\section{Conclusions}

In the paper, the finite element analysis of a typical shear wall element which follows the construction practices applied in Greece during the 70s was presented assuming that a certain crack has been developed as a result of an earthquake action. The crack was modelled following tools from the theory of fractals. Three different resolutions of the fractal crack were considered by taking into account the aggregate sizes of the concrete, and their results were compared to those of the initially uncracked wall. The main finding of the paper is that the cracked wall still has the capacity to sustain monotonic horizontal loading. For small axial loading values, this capacity is similar to that of the initially uncracked wall. However, for larger axial loading values where the 

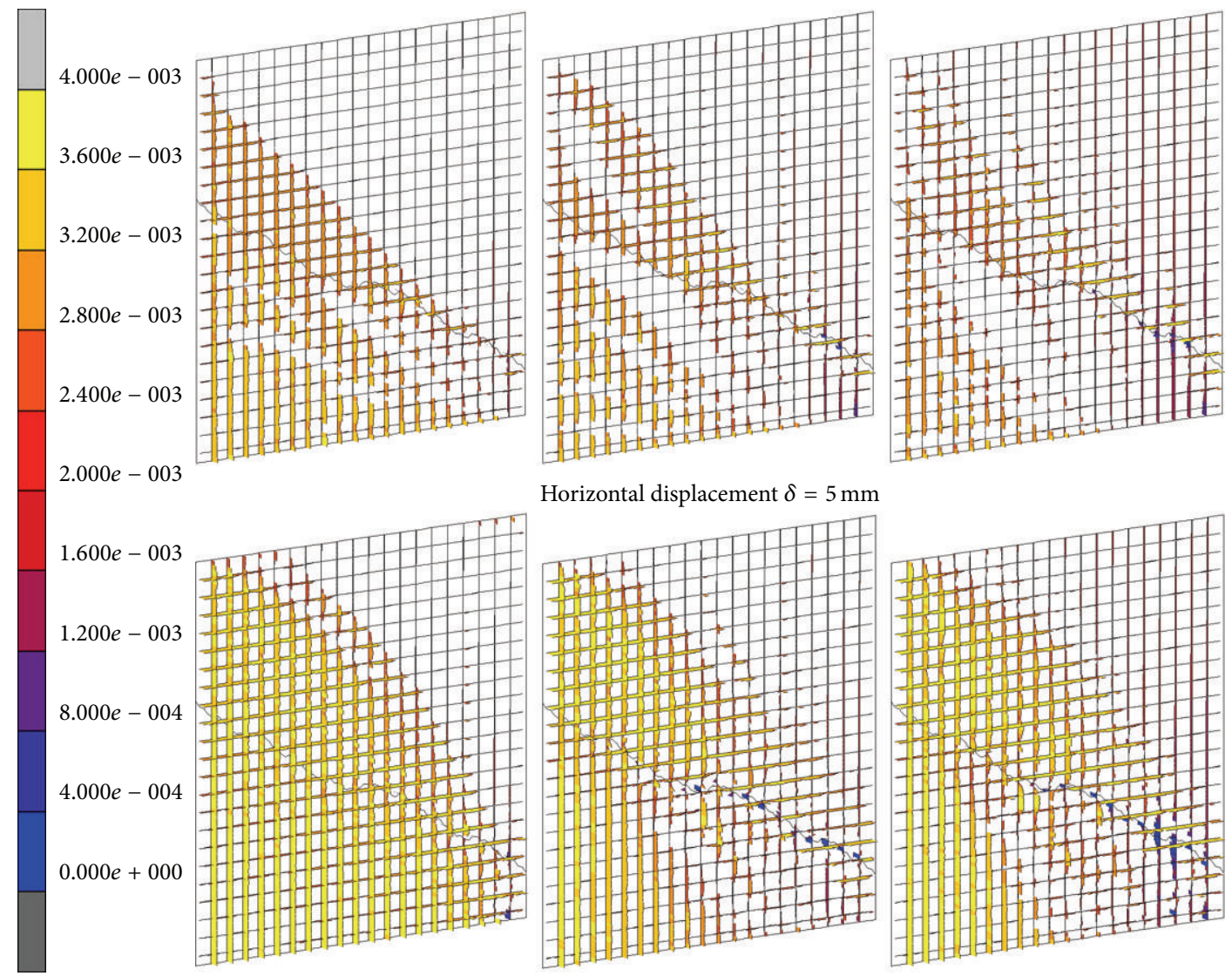

Horizontal displacement $\delta=5 \mathrm{~mm}$
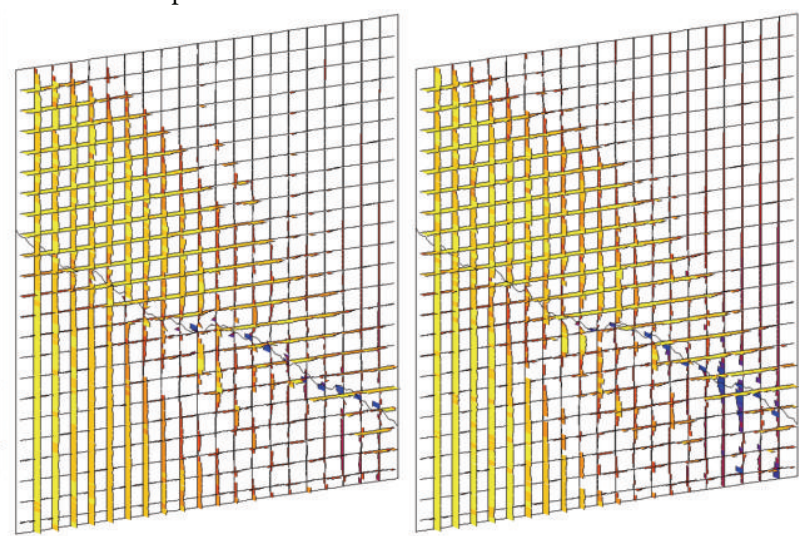

Horizontal displacement $\delta=20 \mathrm{~mm}$

FIGURE 12: Forces developed in the steel mesh for various values of the vertical loading for the 4th resolution of the crack (left column: $N=500 \mathrm{kN}$, middle column: $N=1500 \mathrm{kN}$, and right column: $N=2500 \mathrm{kN}$ ).

demands increase, it seems that a more accurate simulation of the geometry of the fractal crack (i.e., considering higher values of the resolution of the interfaces) leads to better results. Using lower resolution values, the roughness of the interfaces is not taken into account, and therefore the mechanical interlock between the two faces of the crack is rather limited, leading the concrete in the vicinity of the crack to overstressing and gradually to a complete loss of its capacity to sustain any kind of forces. In this case the bending capacity of the wall is significantly limited.

\section{References}

[1] H.-G. Sohn, Y.-M. Lim, K.-H. Yun, and G.-H. Kim, "Monitoring crack changes in concrete structures," Computer-Aided Civil and Infrastructure Engineering, vol. 20, no. 1, pp. 52-61, 2005.

[2] T. C. Hutchinson and Z. Chen, "Image-based framework for concrete surface crack monitoring and quantification," Advances in Civil Engineering, vol. 2010, Article ID 215295, 2010.

[3] B. B. Mandelbrot, D. E. Passoja, and A. J. Paullay, "Fractal character of fracture surfaces of metals," Nature, vol. 308, no. 5961, pp. 721-722, 1984.

[4] V. E. Saouma, C. C. Barton, and N. A. Gamaleldin, "Fractal characterization of fracture surfaces in concrete," Engineering Fracture Mechanics, vol. 35, no. 1-3, pp. 47-53, 1990.
[5] A. Majumdar and C. L. Tien, "Fractal characterization and simulation of rough surfaces," Wear, vol. 136, no. 2, pp. 313-327, 1990.

[6] V. E. Saouma and C. C. Barton, "Fractals, fractures, and size effects in concrete," Journal of Engineering Mechanics, vol. 120, no. 4, pp. 835-854, 1994.

[7] A. Carpinteri and B. Chiaia, "Multifractal nature of concrete fracture surfaces and size effects on nominal fracture energy," Materials and Structures, vol. 28, no. 8, pp. 435-443, 1995.

[8] B. Chiaia, J. G. M. Van Mier, and A. Vervuurt, "Crack growth mechanisms in four different concretes: microscopic observations and fractal analysis," Cement and Concrete Research, vol. 28, no. 1, pp. 103-114, 1998.

[9] H. Mihashi, N. Namura, and T. Umeoka, "Fracture mechanics parameters of cementitious composite materials and fractured surface properties," in Europe-U.S. Workshop on Fracture and Damage in Quasibrittle Structures, Prague, Czech Republic, 1994.

[10] A. Carpinteri and P. Cornetti, "Size effects on concrete tensile fracture properties: an inter-pretation of the fractal approach based on the aggregate grading," Journal of the Mechanical Behavior of Biomedical Materials, vol. 13, no. 3-4, pp. 233-246, 2011.

[11] H.-Q. Sun, J. Ding, J. Guo, and D.-L. Fu, "Fractal research on cracks of reinforced concrete beams with different aggregates 
sizes," Advanced Materials Research, vol. 250-253, pp. 1818-1822, 2011.

[12] V. Mechtcherine, "Fracture mechanical behavior of concrete and the condition of its fracture surface," Cement and Concrete Research, vol. 39, no. 7, pp. 620-628, 2009.

[13] M. Borri-Brunetto, A. Carpinteri, and B. Chiaia, "Scaling phenomena due to fractal contact in concrete and rock fractures," International Journal of Fracture, vol. 95, no. 1-4, pp. 221-238, 1999.

[14] O. Panagouli and E. Mistakidis, "Dependence of contact area on the resolution of fractal interfaces in elastic and inelastic problems," Engineering Computations, vol. 28, no. 6, pp. 717746, 2011.

[15] E. Mistakidis and G. Stavroulakis, Nonconvex Optimization in Mechanics. Algorithms, Heuristic and Engineering Applications by the FEM, Kluwer, 1997.

[16] A. Carpinteri, B. Chiaia, and S. Invernizzi, "Three-dimensional fractal analysis of concrete fracture at the meso-level," Theoretical and Applied Fracture Mechanics, vol. 31, no. 3, pp. 163-172, 1999.

[17] G. Mourot, S. Morel, E. Bouchaud, and G. Valentin, "Anomalous scaling of mortar fracture surfaces," Physical Review E, vol. 71, no. 1, Article ID 016136, 2005.

[18] A. Carpinteri, G. Lacidogna, and G. Niccolini, "Fractal analysis of damage detected in concrete structural elements under loading," Chaos, Solitons \& Fractals, vol. 42, no. 4, pp. 20472056, 2009.

[19] B. Mandelbrot, The Fractal Geometry of Nature, W.H. Freemann, 1982.

[20] B. B. Mandelbrot, "Self-affine fractals and fractal dimension," Physica Scripta, vol. 32, no. 4, pp. 257-260, 1985.

[21] K. J. Måløy, A. Hansen, E. L. Hinrichsen, and S. Roux, "Experimental measurements of the roughness of brittle cracks," Physical Review Letters, vol. 68, no. 2, pp. 213-215, 1992.

[22] A. Majumdar and B. Bhushan, "Role of fractal geometry in roughness characterization and contact mechanics of surfaces," Journal of Tribology, vol. 112, no. 2, pp. 205-216, 1990.

[23] P. D. Panagiotopoulos and O. K. Panagouli, "Fractal geometry in contact mechanics and nu-merical applications," in CISMBook on Scaling, Frac-Tals and Fractional Calculus in Continum Mechanics, A. Carpintieri and F. Mainardi, Eds., pp. 109-171, Springer, 1997.

[24] F. M. Borodich and D. A. Onishchenko, "Similarity and fractality in the modelling of roughness by a multilevel profile with hierarchical structure," International Journal of Solids and Structures, vol. 36, no. 17, pp. 2585-2612, 1999.

[25] F. M. Borodich and A. B. Mosolov, "Fractal roughness in contact problems," Journal of Applied Mathematics and Mechanics, vol. 56, no. 5, pp. 681-690, 1992.

[26] E. S. Mistakidis and O. K. Panagouli, "Strength evaluation of retrofit shear wall elements with interfaces of fractal geometry," Engineering Structures, vol. 24, no. 5, pp. 649-659, 2002.

[27] E. S. Mistakidis and O. K. Panagouli, "Friction evolution as a result of roughness in fractal interfaces," Engineering Computations, vol. 20, no. 1-2, pp. 40-57, 2003.

[28] C.-J. Chen, T.-Y. Lee, Y. M. Huang, and F.-J. Lai, "Extraction of characteristic points and its fractal reconstruction for terrain profile data," Chaos, Solitons \& Fractals, vol. 39, no. 4, pp. 17321743, 2009.

[29] M. Barnsley, Fractals Everywhere, Academic Press, 1988.
[30] G.-D. Hu, P. D. Panagiotopoulos, P. Panagouli, O. Scherf, and P. Wriggers, "Adaptive finite element analysis of fractal interfaces in contact problems," Computer Methods in Applied Mechanics and Engineering, vol. 182, no. 1-2, pp. 17-37, 2000.

[31] R. de Borst, J. J. C. Remmers, A. Needleman, and M.-A. Abellan, "Discrete vs smeared crack models for concrete fracture: bridging the gap," International Journal for Numerical and Analytical Methods in Geomechanics, vol. 28, no. 7-8, pp. 583-607, 2004. 


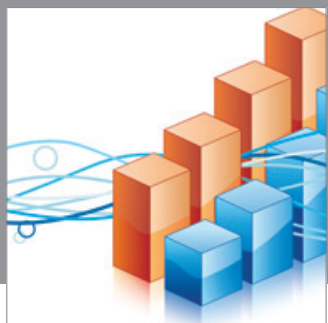

Advances in

Operations Research

mansans

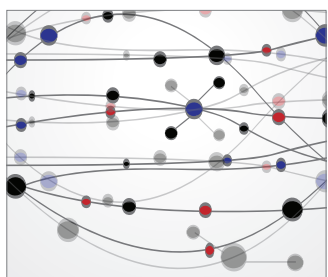

The Scientific World Journal
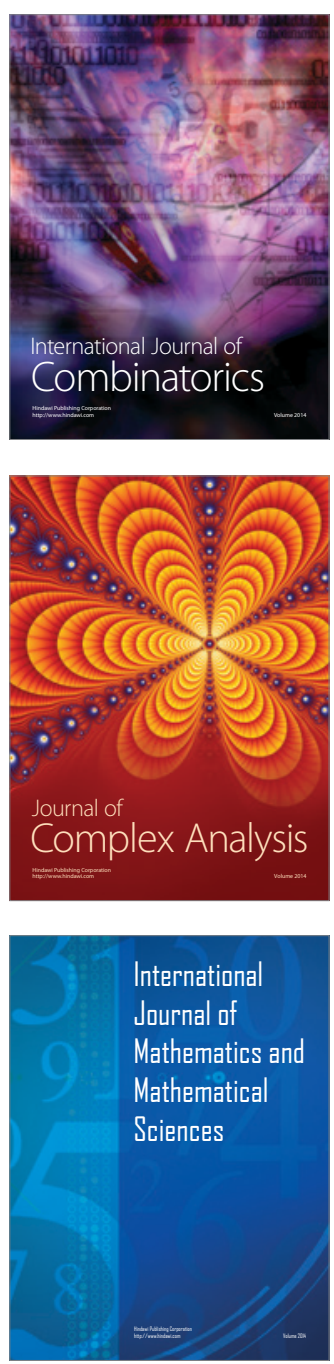
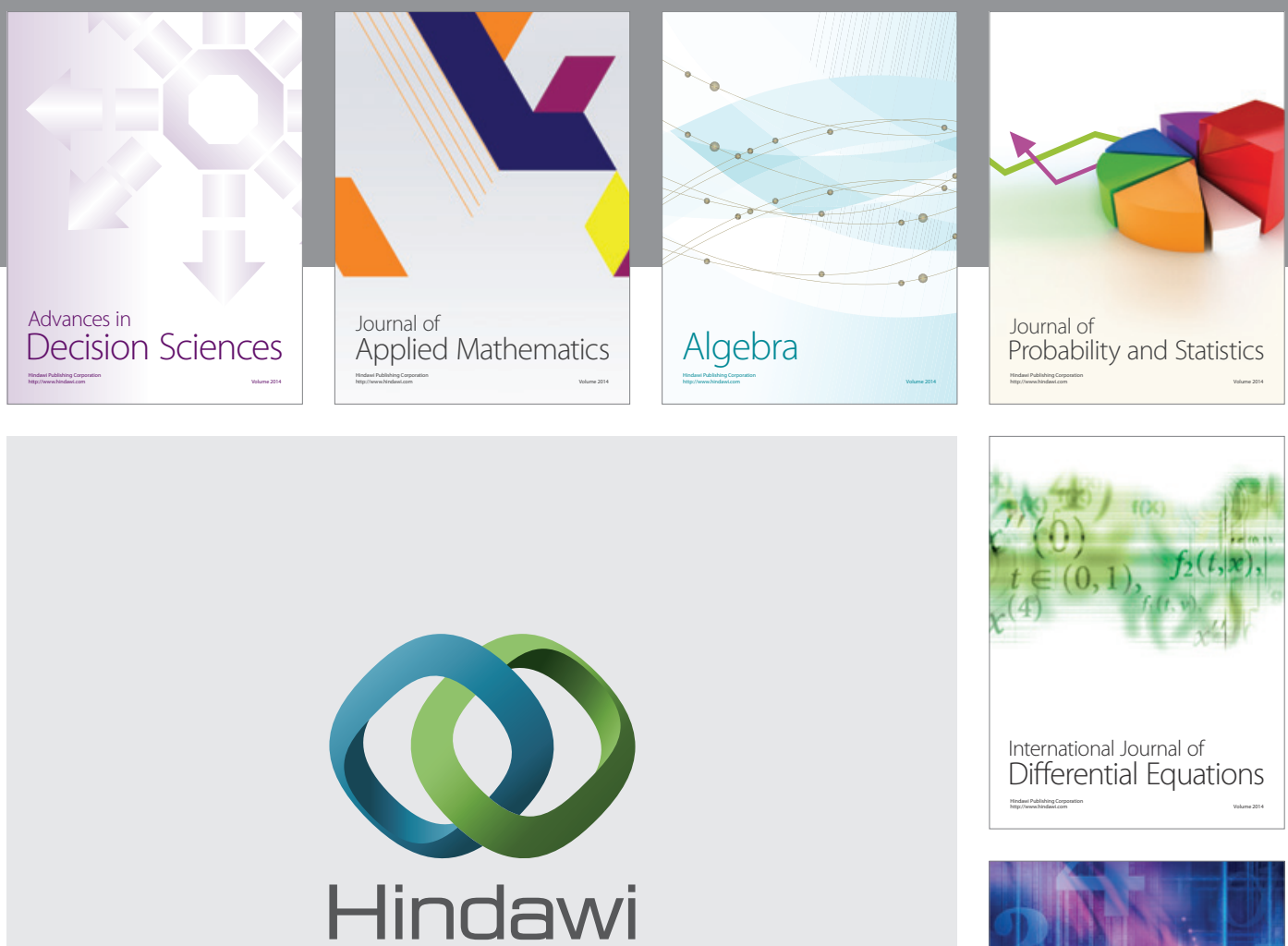

Submit your manuscripts at http://www.hindawi.com
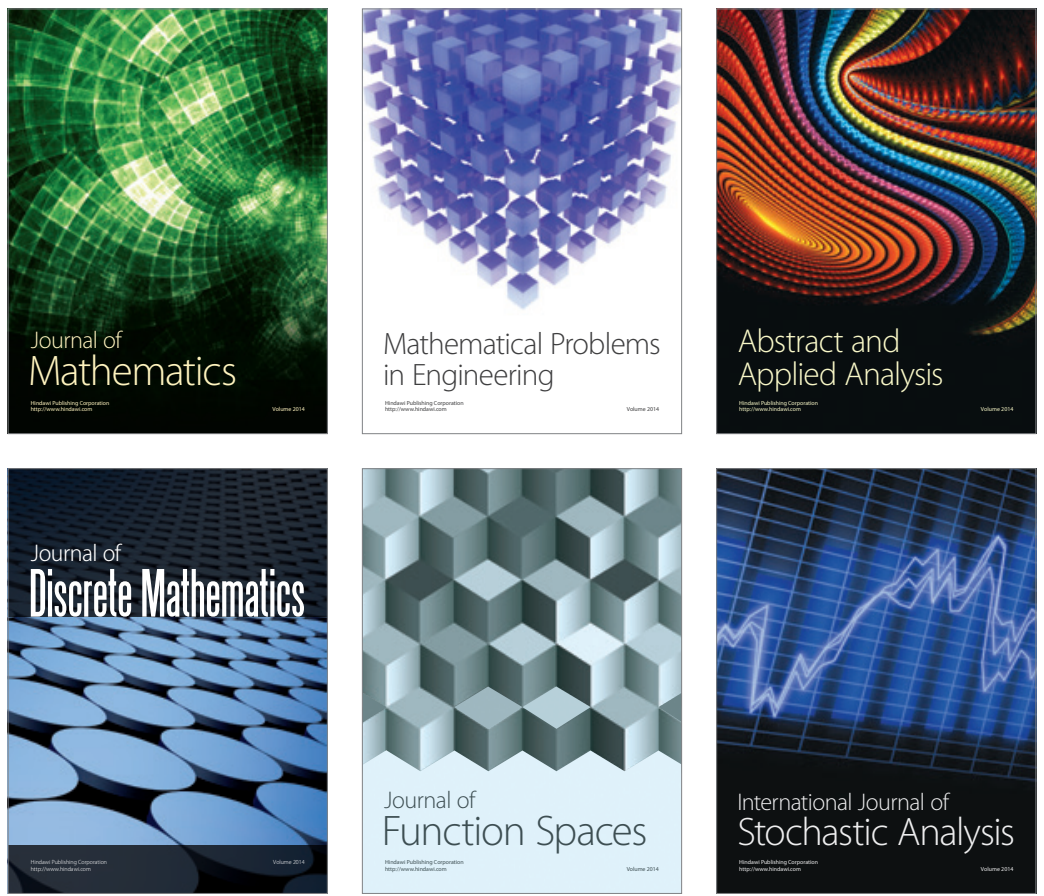

Journal of

Function Spaces

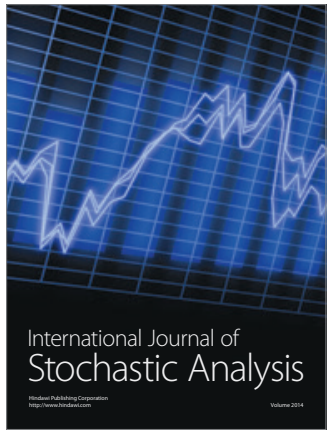

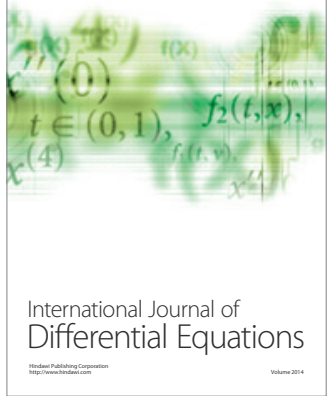
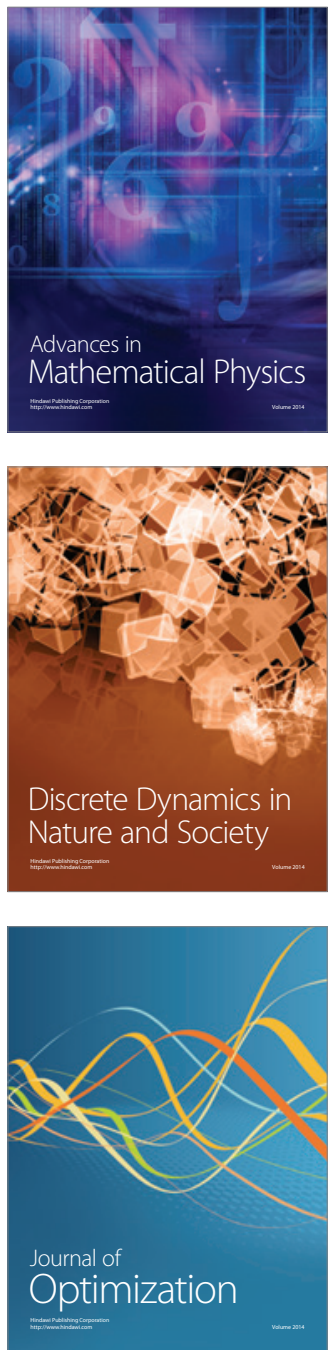